\title{
Resistance of Pinus taeda families under artificial inoculations with diverse fusiform rust pathogen populations and comparison with field trials
}

\author{
Fikret Isik, Henry V. Amerson, Ross W. Whetten, Saul A. Garcia, Bailian Li, and \\ Steven E. McKeand
}

\begin{abstract}
Controlled inoculations with 10 bulk inocula of Cronartium quercuum (Berk) Miyabe ex Shirai f.sp. fusiforme were carried out on open-pollinated progeny of 25 fast-growing Pinus taeda L. parents. The parents had a range of breeding values for resistance to fusiform rust in progeny field trials. There were highly significant differences among the halfsib families in response to inoculations, and these differences were very reproducible; the half-sib family-mean heritability of resistance to controlled inoculation was 0.97 . All of the families that were susceptible in the field were susceptible in controlled inoculations, and most (12 of 17) of the field-resistant families were resistant in response to controlled inoculations. Significant pathogenic variability was observed among the different bulk inocula, although this accounted for only $1.9 \%$ of the total variation. Genetic differences among families within field-resistant or field-susceptible groups accounted for $13.7 \%$ of the total variation. The family by inocula interaction was highly significant, but a single field-resistant family contributed $44 \%$ of the total family by inocula interaction variance, and two other field-resistant families also showed significant interactions.
\end{abstract}

Résumé : Des tests d'inoculation contrôlée avec 10 sources d'inoculum de Cronartium quercuum (Berk) Miyabe ex Shirai f. sp. fusiforme ont été effectués sur des descendances issues de pollinisation libre et provenant de 25 parents de Pinus taeda L. à croissance rapide. Les parents représentaient une gamme de valeurs génétiques pour la résistance à la rouille fusiforme dans des tests de descendance sur le terrain. Il y avait des différences significatives parmi les descendances uniparentales en réaction aux inoculations et ces différences étaient très reproductibles; l'héritabilité moyenne des descendances uniparentales pour la résistance aux inoculations contrôlées était de 0,97. Toutes les familles qui étaient sensibles sur le terrain étaient également sensibles dans les essais d'inoculation contrôlée et la plupart (12 sur 17) de celles qui étaient résistantes sur le terrain étaient également résistantes dans les essais d'inoculation contrôlée. Une variation significative de la pathogénicité a été observée parmi les sources d'inoculum bien que cela ne représentait que 1,9\% de la variation totale. Les différences génétiques entre les familles parmi les groupes de familles résistantes ou sensibles sur le terrain représentaient $13,6 \%$ de la variation totale. L'interaction famille $\times$ source d'inoculum était très significative mais une famille contribuait à elle seule $44 \%$ de la variation de l'interaction famille $\times$ source d'inoculum qui était également significative chez deux autres familles résistantes sur le terrain.

[Traduit par la Rédaction]

\section{Introduction}

Fusiform rust disease, caused by Cronartium quercuum (Berk) Miyabe ex Shirai f.sp. fusiforme (Cqf), is manifested by swollen regions called galls on stems or branches of pines, and is commonly recognized as the most economi-

Received 22 February 2008. Accepted 12 August 2008.

Published on the NRC Research Press Web site at cjfr.nrc.ca on 30 September 2008.

F. Isik, ${ }^{1}$ R.W. Whetten, S.A. Garcia, and S.E. McKeand.

Cooperative Tree Improvement Program, Department of Forestry and Environmental Resources, Box 8002, North Carolina State

University, Raleigh, NC 27695-8002, USA.

H.V. Amerson. Retired. Department of Forestry and

Environmental Resources, Box 7247, North Carolina State

University, Raleigh, NC 27695-7247, USA.

B. Li. Cooperative Tree Improvement, currently Vice Provost, International Affairs, Box 7112, North Carolina State University, Raleigh, NC 27695-7112, USA.

${ }^{1}$ Corresponding author (e-mail: fisik@ncsu.edu). cally important disease of loblolly pine (Pinus taeda L.) and slash pine (Pinus elliottii Engelm.) in the southern United States (Kinloch and Stonecypher 1969; Powers et al. 1981; Anderson et al. 1986; Kuhlman 1992). Annual losses from this disease are estimated in the range of US\$24 to US\$135 million (Cubbage et al. 2000).

Substantial genetic variation in expression of host resistance to fusiform rust is present in both slash and loblolly pine (Schmidt et al. 1981; Walkinshaw and Bey 1981; Powers and Kraus 1986; Kuhlman and Powers 1988). Use of resistant planting stock is the only feasible means of controling fusiform rust disease in the forest environment (Kinloch and Walkinshaw 1991), particularly in pine plantations in the southeastern United States. Identification and deployment of pine families with enhanced resistance to fusiform rust across a broad range of sites are critical if the full benefits of breeding programs are to be realized.

Traditionally, pine breeding programs have tested families in field trials. Rust breeding values have been estimated based on the progeny performance for fusiform rust disease 
using polygenic models that assume many genes, each with small effects on disease resistance (Isik et al. 2005). Development of fusiform rust disease in field trials is sporadic and can vary greatly from one year to another or from one site to another (McKeand et al. 1999; Li 2003), because the frequency and density of inoculation, the genetic variability of the pathogen population, and climatic conditions cannot be controlled in these field trials. Under the field circumstances described above, pine families with relatively low frequencies of fusiform rust disease compared with susceptible checks and other families have been defined as field resistant, whereas families with relatively high frequencies of fusiform rust disease have been considered field-susceptible families.

Pathogenic variability among $C q f$ inocula can be a complicating component in field evaluations for fusiform rust, as the fungal source cannot be controlled in natural field inoculations (Snow et al. 1975; Powers et al. 1977; Kuhlman 1992). Since the mid 1970s, the USDA Forest Service has been routinely screening pine seedlings at the Resistance Screening Center (RSC) in Asheville, North Carolina, in an effort to select rust-resistant families to deploy in diseasehazard areas in the southern United States. If inoculations are conducted in controlled greenhouse environments with a constant inoculum load, as practiced at the RSC, genetic variation in the pathogen can be controlled and estimated. Controlled Cqf inoculations of pines can be carried out either with solutions of fungal basidiospores derived from a mixture of different fungal genotypes, or with basidiospores prepared from an individual fungal strain or line, referred to as a single genotype line. A single genotype line, previously called a single aeciospore isolate (e.g., Powers 1980; Kuhlman and Matthews 1993), is an asexually multiplied line of urediniospores, a single dikaryotic genotype that traces its origin to a single dikaryotic aeciospore. Use of single genotype lines, or single aeciospore isolates, of the rust pathogen greatly reduces genetic variability in the basidiospore population used for pine inoculations and has allowed identification of a single genetic locus, Frl, that behaved as a single gene having a major effect on host resistance to fusiform rust disease (Wilcox et al. 1996). A dominant allele at the Frl locus was shown to confer resistance against one single genotype line of the rust pathogen (avirulent against Frl resistance) and to lack effectiveness against another single genotype line that was virulent against Frl resistance (Wilcox et al. 1996). Later work with the same Frl allele in an offspring of the 10-5 female pine parent used by Wilcox et al. (1996) reported that the resistance conferred by this allele remained stable under increasing density of spore inoculum, provided that inoculation used a single genotype line of the pathogen against which the resistance allele is effective (Kuhlman et al. 1997).

Additional work with loblolly pine families from breeding programs extended these findings to identify eight loci with major effects on resistance of loblolly pine to fusiform rust disease (Amerson et al. 2005). These results strongly suggest that at least some of the resistance to fusiform rust disease detected by pine breeding programs in progeny tests can be explained by an oligogenic model of a few dominant alleles with major effects, rather than the many alleles with small additive effects assumed by the polygenic model. It is not yet clear whether the oligogenic model can explain most or all of the variation in rust resistance detected in progeny tests carried out by loblolly pine breeding programs, or if polygenic mechanisms contribute some portion of the disease resistance detected in field tests.

In a series of field trials across a range of disease levels - in 28 tests from North Carolina to Louisiana, mean gall occurrence of tests ranged from $17 \%$ to $74 \%$ - rust resistance levels for the various families were generally consistent across sites (Li and McKeand 1989; McKeand et al. 1999). Further analysis of the same data set showed that resistance to fusiform rust disease was unpredictable across sites for the families deemed most resistant (McKeand et al. 2003), but not for susceptible families. On average, any one family's level of disease (percentage of individuals with galls) was reasonably predictable for any given infection level at a given site; the mean coefficient of determination $\left(r^{2}\right)$ was 0.78 for the regression of family means versus site means for rust disease. However, six of the families with the lowest overall disease incidence had the lowest $r^{2}$ values (mean $r^{2}=0.58$ ) (McKeand et al. 2003). Some of the observed variation in resistance within families across sites may be due to interactions of major-effect host resistance factors with genetic variation in different pathogen populations at the different sites. A study of pine progeny test data that compared the fit of a mixed-inheritance model that included both polygenic and oligogenic effects, with the fit of a model that included only polygenic effects, concluded that the mixed inheritance model with both oligogenic and polygenic effects better described host disease resistance ( $\mathrm{Li}$ et al. 2006).

In the present study, we examined variation among pathogen inocula sources, disease incidence in field-resistant and field-susceptible families, and the stability of rust resistance in controlled greenhouse inoculations using selected candidate loblolly pine families and diverse inoculum sources. The following questions were investigated: (1) What is the relative contribution of host genetics (family differences) to the total phenotypic variation? (2) How much of the variation in disease response can be explained by the geographic sources of pathogen populations? (3) Do these highly productive families show significant interactions with the different inocula or are they stable (not significantly interactive) across inocula?

\section{Materials and methods}

\section{Half-sib families}

The North Carolina State University Cooperative Tree Improvement Program (the Cooperative) manages loblolly pine improvement programs in the southeastern United States to increase wood yield and quality in pine plantations. In its second cycle of progeny testing, the Cooperative tested parents in several series of disconnected partial-diallel tests. Families within each test series were replicated at four locations within a limited geographic range (see McKeand et al. (2008) for details). After six growing seasons in the field, the progeny tests were measured and breeding values for height, diameter, stem straightness, and fusiform rust disease were predicted (Xiang and Li 2001).

Using the diallel mating design and field progeny test results, we identified 25 fast-growing parents with a wide 
Fig. 1. Geographic locations of collection sites in the southeastern United States for the 10 Cronartium quercuum fusiforme f.sp. inocula (301-310) used in this study are highlighted in dark gray. The natural range of loblolly pine is denoted by the lighter gray areas of the map.

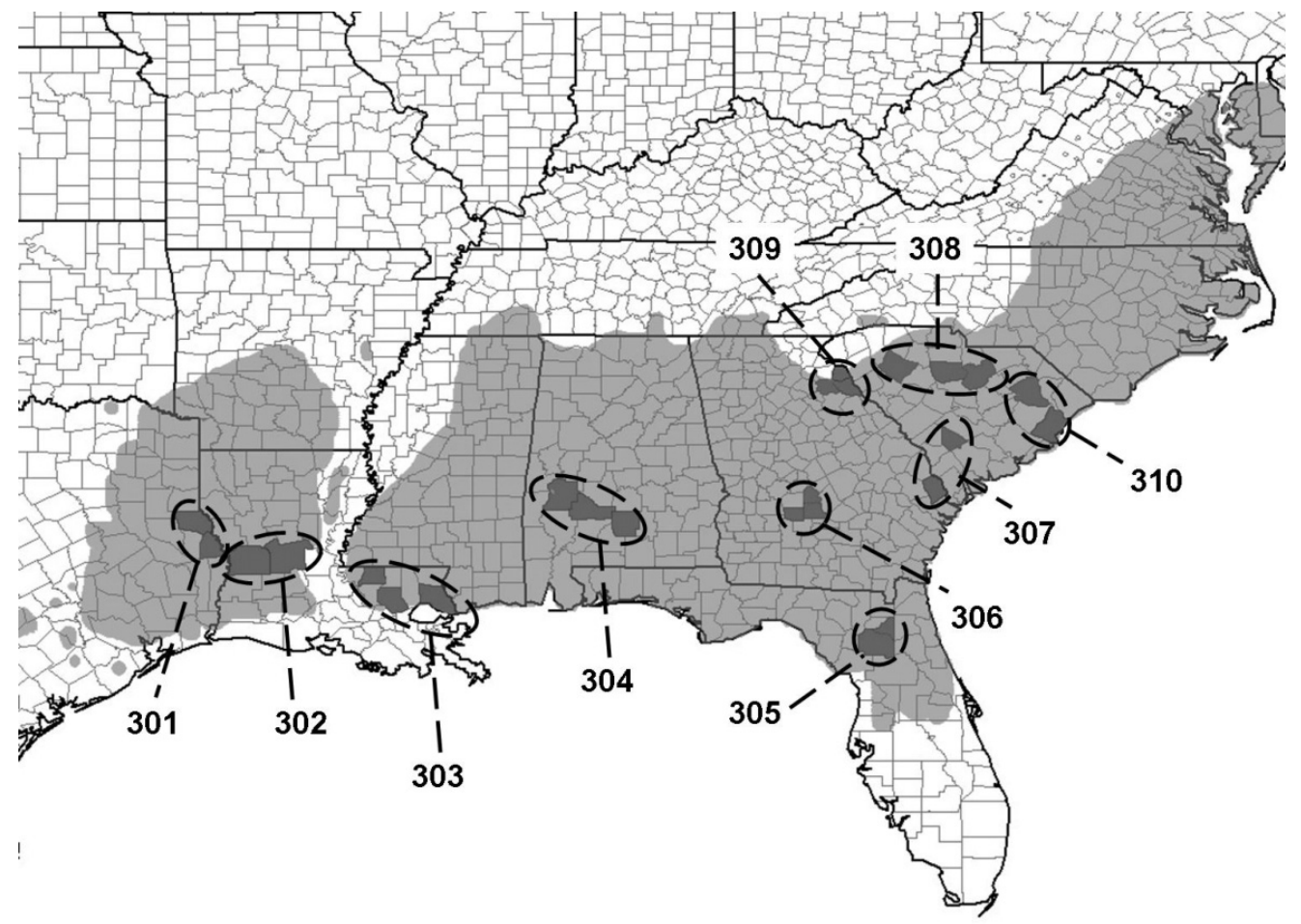

range of rust resistance breeding values. The mean disease incidence (gall formation) in the field trials where parents had been tested ranged from $33 \%$ to $56 \%$. The selected parents originated from the South Atlantic and Gulf Coastal Plains of the United States. These parents are not related to those used in previous studies (e.g., McKeand et al. 2003). Among the parents selected for greenhouse inoculations, 17 were field resistant (rust breeding values averaged 5\%) and eight were field susceptible (rust breeding values averaged $64 \%$ ). We consider the selected parents "field resistant" or "field susceptible" because the predicted breeding values for rust disease were based on field tests (with inocula from narrow geographic ranges), rather than on tests with geographically diverse sources of pathogen, as is routinely possible in controlled greenhouse inoculations. In addition to 25 fast-growing families used in the greenhouse screening, we also included a standard check lot (No. 39, a bulk seed collection from unimproved loblolly pine) in greenhouse inoculation experiments. This check lot is used routinely at the RSC in Asheville, North Carolina, where it is considered a susceptible check, and we used the RSC convention.

\section{Pathogen}

This study, following standard RSC protocols (Knighten et al. 1988), used inocula from 10 different geographic collection areas in the southern United States (Fig. 1). Aeciospores were used to infect northern red oak (Quercus rubra L., the alternate host for the fungus Cqf) seedlings for the production of basidiospores that were used to inoculate pine seedlings. The aeciospore inocula were obtained from the RSC inventory of field collections. They were collected between 1985 and 2004 as part of the RSC inoculum collection program. Each of the inocula was a 30 gall mix, derived by blending 10 gall collections from three different sites within a collection area (see Knighten et al. (1988) for collection protocols). The distance between sites within a collection area was variable over several kilometres. The large number of galls per inoculum should have enhanced the opportunity to capture much of the pathogen diversity in a given region or pathogen population.

\section{Experimental design and greenhouse inoculations}

Stratified open-pollinated seeds (collected from multiple seed orchards) of the 25 test parents were germinated in a greenhouse in spring 2004. Seedlings were grown and maintained at the RSC until inoculation. The open-pollinated progeny of 25 parents, plus a susceptible check lot (No. 39) were rust challenged in a greenhouse environment at the RSC using standard RSC procedures (Knighten et al. 1988). For each parent, 60 progeny (seedlings) were to be challenged with 10 inocula (30-gall mixes from 10 different RSC collection areas). The experimental design was a randomized complete block with three blocks. Each openpollinated family was to be represented by 20 progeny in each block (tray) for a total of 600 progeny, yielding, in theory, 15600 (experimental and check lot) study progeny. However, as a result of lower germination rates and survival, a total of 14875 seedlings were actually assessed for fusiform rust disease. A standard spore density of 20000 basidiospores $/ \mathrm{mL}$ was used for all the inocula. Seedlings were inoculated with $C q f$ basidiospores approximately 8 weeks after seed sowing and then grown for six months before disease (gall) assessment. The occurrence of galls was recorded as a binary trait: 1, gall (diseased); 0, no gall (considered nondiseased). 


\section{Statistical analysis}

Disease incidence was observed as a binary variable that follows a Bernoulli distribution. For such a distribution, the mean is $\mathrm{E}(X)=\pi$ and the variance is $\operatorname{Var}(X)=\pi(1-\pi)$, where $X$ is the number of diseased trees. In this case we are interested in the estimated $\pi_{i}$, which is the sample mean $(\widehat{\pi}=X / n)$, where $n$ is the total number of trees. Fitting a general linear model to a binary data distribution violates the assumptions of the standard linear mixed model and may produce estimates outside the range of permissible values. We therefore invoked the threshold concept to estimate variance components for rust disease, which assumes an underlying, nonobservable normal distribution for the discrete phenotypic variable (Falconer and Mackay 1996). The probability of disease $\left(y_{m i j k l}\right)$ for a single tree was modeled with the generalized linear mixed model using a logit (canonical) link function to estimate variance components. The model fit across all data is given in eq. 1 , and in eq. 2 in matrix form.

$$
\begin{aligned}
{[1] \quad y_{m i j k l} } & =\log [\pi /(1-\pi)] \\
& =\mu+T_{m}+I_{i}+B(I)_{i j}+F_{k}(T)_{m}+F I_{i k}(T)_{m}+E_{m i j k}
\end{aligned}
$$

$$
\text { [2] } \boldsymbol{y}=\boldsymbol{\eta}+\boldsymbol{e}=\mathbf{X} \beta+\mathbf{Z} \boldsymbol{u}+\boldsymbol{e}
$$

where $y_{m i j k l}$ is the $l$ th observation of the $k$ th family of the $m$ th type (field-susceptible or field-resistant family) challenged with the $i$ th inocula in the $j$ th block; $\pi$ is the proportion of diseased trees; $\mu$ is the conditional mean; $\boldsymbol{y}$ is the vector of observations; $\boldsymbol{\eta}$ is a linear predictor $(\boldsymbol{\eta}=\mathbf{X} \boldsymbol{\beta}+$ $\mathbf{Z} \boldsymbol{u}$, expressed through an inverse link function); $\boldsymbol{\beta}$ is the vector of fixed effects, which includes the conditional mean, the $m$ th family-type effect $\left(T_{m}\right.$ for the susceptible and resistant families), and the $j$ th block effect $\left(B_{j}\right) ; \mathbf{X}$ is the design matrix relating fixed effects to the elements of $\boldsymbol{y}$; $\boldsymbol{u}$ is the vector of random effects, which includes the $i$ th inocula effect $\left(I_{i}\right)$, the $k$ th family effect $\left(F_{k}\right)$, and the $k$ th family by $i$ th inocula interaction $\left(F I_{i k}\right)$ effect. The $F_{k}$ and $F I_{i k}$ terms are nested within the type effect; $\mathbf{Z}$ is the design matrix relating random effects to the elements of $\boldsymbol{y} ; E_{m i j k l}$ is the random residual associated with the $l$ th observation; and $\boldsymbol{e}$ is the vector of residuals.

The random terms are assumed to be uncorrelated with means equal to zero and independent variances, expressed as $\mathrm{N}\left(0, \mathbf{I} \sigma_{I}^{2}\right), \mathrm{N}\left(0, \mathbf{I} \sigma_{F(T)}^{2}\right)$, and $\mathrm{N}\left(0, \mathbf{I} \sigma_{F I(T)}^{2}\right.$ (Schall 1991), where $\mathbf{I}$ is the identity matrix. The random effects are also assumed to be uncorrelated with the residuals $(\boldsymbol{e})$. The covariance matrix of $\boldsymbol{\eta}$ is $\operatorname{Cov}(\boldsymbol{\eta})=\mathbf{Z G Z} \mathbf{Z}^{T}+\mathbf{R}$, where $\mathbf{G}=\sigma_{u}^{2} \mathbf{I}$ is the diagonal matrix of random effects $\boldsymbol{u}$, and $\mathbf{R}=\sigma_{e}^{2} \mathbf{I}$ is the diagonal random errors variance (Schall 1991). $\mathbf{G}=$ $\operatorname{var}(\boldsymbol{u})$ would be a function of several covariance components, including the family effects (Tempelman 1998). The generalized linear mixed model was run with the GLIMMIX procedure of the SAS software (SAS Institute Inc. 1996).

The validity of the model and the additive genetic variance estimates are closely related to the mean rust disease incidence in the data. Data with a mean incidence of less than 0.3 or greater than 0.7 are not considered informative for the estimation of variance components for a binary trait, because of nonlinearity in the model (see Lynch and Walsh
Table 1. Results of the fixed model used to detect the effects of pathogen populations (inocula) on the disease level, the overall response of host families, and pathogen by pine family interactions.

\begin{tabular}{lrrrr}
\hline Source & df & $\begin{array}{l}\text { Mean } \\
\text { squares }\end{array}$ & $F$ & $P>F$ \\
\hline Inocula & 9 & 0.271 & 20.1 & $<0.001$ \\
Block(inocula) $_{\text {Type }^{a}}$ & 20 & 0.020 & 1.5 & 0.093 \\
Family(type) & 1 & 10.532 & 782.5 & $<0.001$ \\
Type $\times$ inocula & 23 & 0.786 & 58.4 & $<0.001$ \\
Inocula $\times$ family(type) & 18 & 0.035 & 2.6 & 0.006 \\
Error & 207 & 0.026 & 1.9 & $<0.001$ \\
\hline
\end{tabular}

Note: The check lot was excluded from analysis. The fixed linear model was fit to plot percentages of pine families for disease incidence.

${ }^{a}$ Resistant versus susceptible.

(1998), Chap. 25, and Gilmour et al. (1985)). Mean rust disease incidence for each inoculum in our study ranged from 0.35 to 0.57 , suggesting that the mean incidences were within acceptable boundaries. We assume that the open-pollinated families approximate half-sib families, and since the covariances among the half-sibs are known, the half-sib family component is assumed to be $1 / 4$ of additive genetic variance $\left(\sigma_{\mathrm{A}}^{2}\right)$ (Falconer and Mackay 1996). Using the observed variance components from model [1], narrow-sense individual-tree heritability $\left(h_{\mathrm{i}}^{2}\right)$ and the heritability of halfsib family means $\left(h_{\mathrm{hs}}^{2}\right)$ were calculated on the underlying scale across inocula based on the variance among families nested within type as follows:

$$
\begin{aligned}
& \text { [3] } \quad h_{i}^{2}=\frac{4 \sigma_{F(T)}^{2}}{\sigma_{F(T)}^{2}+\sigma_{F I(T)}^{2}+\sigma_{e}^{2}} \\
& {[4] \quad h_{\mathrm{hs}}^{2}=\frac{\sigma_{F(T)}^{2}}{\sigma_{F(T)}^{2}+\frac{\sigma_{F I(T)}^{2}}{t}+\frac{\sigma_{e}^{2}}{t n}}}
\end{aligned}
$$

where $t$ is the number of inocula, and $n$ is the number of progeny per family in an inoculation experiment; $\sigma_{F(T)}^{2}$ is the general combining ability variance, which is assumed to be $1 / 4$ of additive genetic variance, and $\sigma_{e}^{2}$ is the fixed error variance $\left(\sigma_{e}^{2}=3.29\right)$ (Gilmour et al. 1985). In the generalized mixed model, the underlying continuous variable is assumed to be independent of the predictor variables with a fixed variance (Goldstein et al. 2002; Browne et al. 2005). The standard errors of heritabilities were estimated according to the Delta method and using a SAS IML code (Isik et al. 2008).

To investigate family by inoculum interaction, we fit a linear fixed model to plot percentages of disease incidence. The fixed model showed significant family by inocula interaction for disease incidence (Table 1). We also estimated the Shukla's stability variance $\left(\sigma_{\mathrm{i}}^{2}\right)$ for each family. This statistic is an unbiased estimate of the variance of a genotype across environments (Shukla 1972). The Shukla's stability variance partitions the genotype by environment interaction variance and assigns it to individual families. We used a mixed-model approach to calculate Shukla's stability variance for each family as suggested by Kang and Magari (1996) and implemented with the MIXED procedure of 
Fig. 2. Probability of disease values for 10 pathogen populations (inocula) from the southeastern United States tested across study families. The central Georgia population caused the least disease, whereas the North Coastal South Carolina population caused the most disease, with a 0.57 disease level.

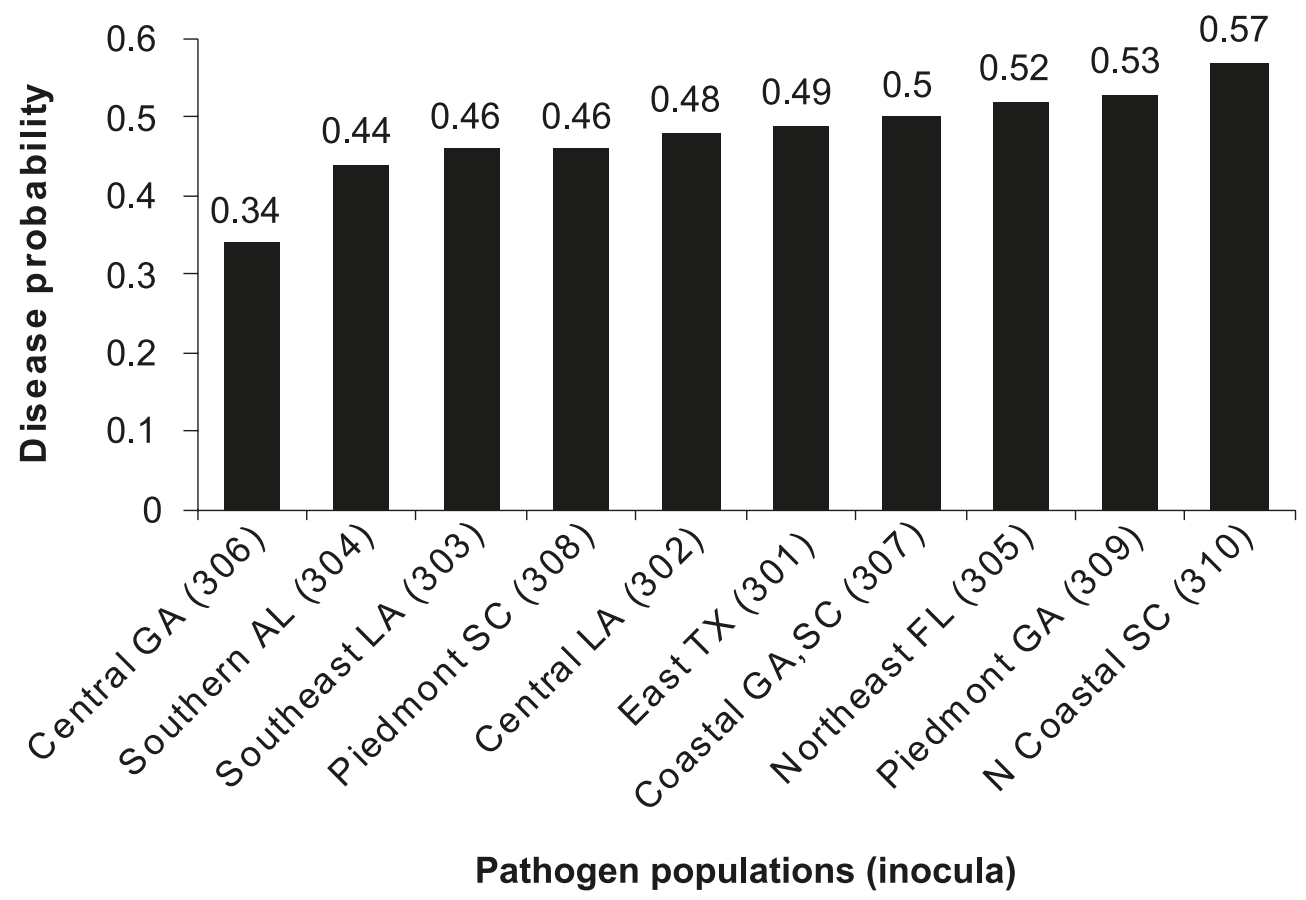

SAS (SAS Institute Inc. 1996). In the model, the inocula, block, and inocula by family interaction (GEI) effects were considered random effects, while the family effects were considered fixed effects. The GEI terms were assumed to have heterogeneous variances by genotype. The restricted maximum likelihood based variance component estimated for each inoculum by family is the same statistic as the Shukla's stability variance (Kang and Magari 1996). The mixed model with heterogeneous GEI allows a different GEI prediction for each family (Saxton 2004). In such analyses, we used plot percentages as the response variable (percent disease of up to 20 progeny per inoculum across 10 inocula). Thus, each family was represented by three values in an experiment and 30 observations across 10 inocula.

\section{Results and discussions}

Variation among pathogen inocula and families

The 10 mixed inocula of fusiform rust, each originating from a different geographic area in the southern United States (Fig. 1), differed significantly with regard to their ability to incite rust disease on loblolly pine seedlings in the greenhouse experiments. This is evident from both a significant inocula (main) effect and the significant inocula by family interaction (Table1). The North Coastal South Carolina inoculum source, with a mean disease probability of 0.57 , caused the most disease collectively across the families, while the central Georgia population caused the least disease, with a mean disease probability of 0.34 (Fig. 2). There was no apparent geographic trend among the pathogen populations for predicted disease probability values.

Family types (e.g., field-resistant and field-susceptible families) were highly different from each other in response to the 10 different inocula $(P<0.001)$ (Table 1$)$. On aver- age, field-resistant families had significantly less disease (0.39) than did field susceptible families (0.64). Family within types (families nested within field-susceptible and field-resistant groups) differed significantly from each other $(P<0.001)$ in disease incidence (Table 1$)$. The relative responses of families to different pathogen populations varied from one pathogen population to another, as shown by the significant inocula by family interaction $(P<0.001)$. This is mainly due to the different levels of response within a single field-resistant family, No. 19. A subset of the field-resistant families (e.g., 30, 29, 22, 20, and 28) had greater rates of disease (breeding value in Fig. 3) compared with the other field-resistant families.

\section{Variance components and heritability estimates}

Variability among the 10 inocula explained $1.9 \%$ of the total variation in disease incidence based on screening of open-pollinated progeny of 25 parents (Table 2). Family within type differences explained a considerably larger amount $(13.7 \%)$ of total variation, indicating significant genetic differences among families in response to pathogen inoculations. The family variance component was estimated as nested within types, i.e., adjusted for differences between field-resistant and field-susceptible groups. The inocula by family interaction term explained $2 \%$ of the total variation. Moderately high narrow-sense individual-tree heritability (0.56) was observed across inocula. However, family means for disease incidence were highly repeatable, as suggested by the high family-mean heritability (0.97). The relationship between the ratio of heritability on the observed and underlying scale is closely related to the mean incidence of the response variable in the data (see Falconer and Mackay (1996), Chap. 18). That relationship is the highest (error is the lowest) when the mean incidence is $P=0.5$ and be- 
Fig. 3. Predicted rust disease breeding values of loblolly pine families from field and greenhouse trials. The light gray bars are predicted disease breeding values based on greenhouse inoculations; the solid black bars are disease breeding values for the same families based on field progeny trials; and the broken bar between the two types of families is the susceptible check lot in greenhouse inoculations. Classification as resistant or susceptible was based on prior field data.

\section{Breeding values from field trials}

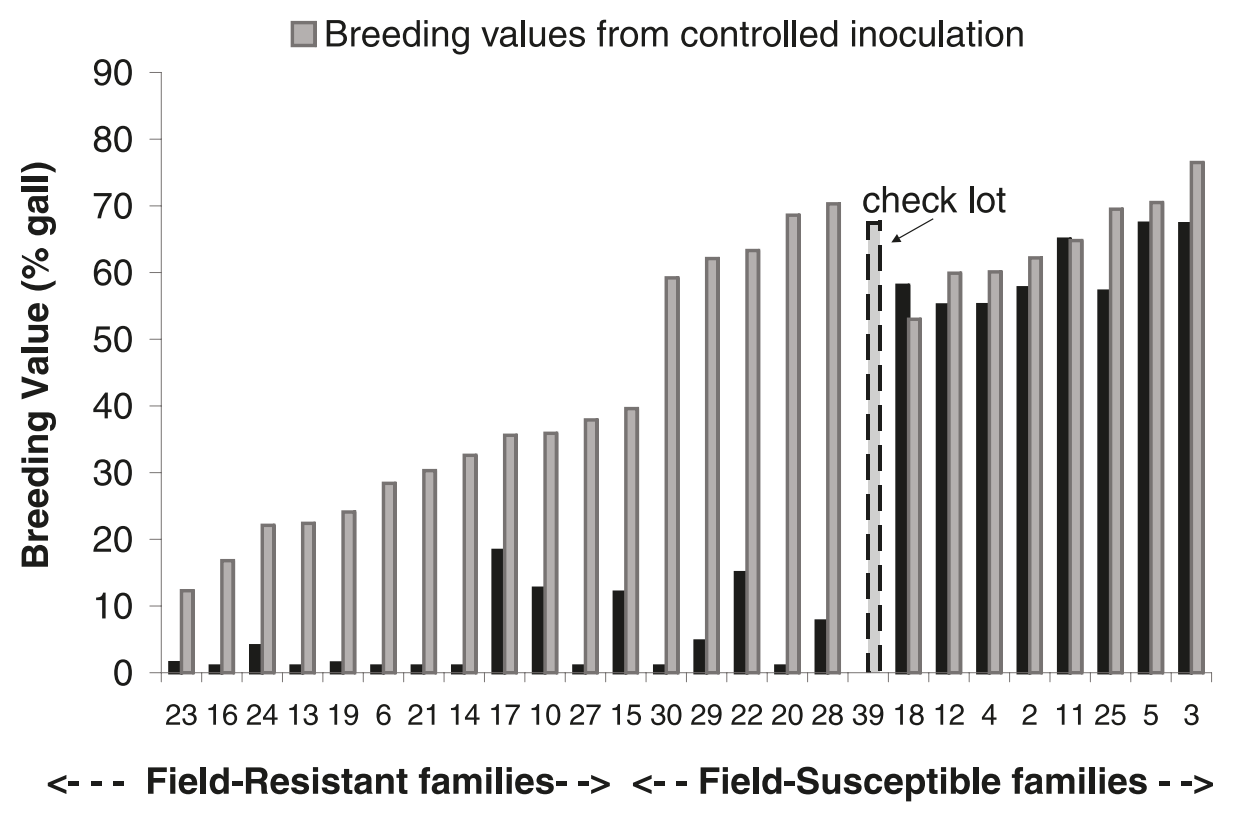

comes larger when $P$ increases or decreases (Lynch and Walsh (1998), Chap. 25). We fit a generalized linear mixed model to binary disease incidence using the canonical link function to transform the disease scores to underlying continuous distribution. Thus, the additive genetic variance and the heritability in our study were calculated as an underlying scale (Gilmour et al. 1985, 1987), without a need to transform from an observed scale to an underlying scale.

The block effect for each experiment explained about $0.1 \%$ of the variation, suggesting that the level of disease from one round of inoculation to another was consistent. Similarly, the plot-to-plot differences (family by block interaction within inocula) explained a small fraction of the total variation $(1.3 \%)$. A large proportion of the total phenotypic variance $(80.9 \%)$ was due to experimental error, such as random tree-to-tree differences for disease.

The within family variance (residual or error variance) is partly genetic and partly unexplained environmental effects on disease development. In a given family of half-sib progeny, only $50 \%$ of the genetic composition (that inherited from the mother tree) would be shared. Excluding paternal resistance inheritance, a population of offspring from a mother tree heterozygous for resistance at a single genetic locus should show about 50\% disease incidence when inoculated under controlled conditions with a pathogen spore population that does not contain spores with virulence against the resistance allele present in the mother tree (Wilcox et al. 1996). If the mother tree has more than one effective major resistance or polygenic mechanisms of resistance, the mode of inheritance becomes more complex, and more variation would be expected among the half-sib progeny (Falconer and Mackay 1996). This is particularly true for mixed inocula such as those used in the experiments reported here,
Table 2. Variance components from the generalized linear mixed model fit to overall data.

\begin{tabular}{llc}
\hline Source and parameters & $\begin{array}{l}\text { Variance } \\
\text { component }\end{array}$ & $\begin{array}{l}\text { \% total variance } \\
\text { explained }\end{array}$ \\
\hline Inocula & $0.079 \pm 0.042$ & 1.9 \\
Block(inocula) & $0.005 \pm 0.005$ & 0.1 \\
Family(type) & $0.557 \pm 0.170$ & 13.7 \\
Inocula $\times$ family(type) & $0.081 \pm 0.018$ & 2.0 \\
Family $\times$ block(inocula) & $0.053 \pm 0.019$ & 1.3 \\
Error & 3.29 (fixed) & 80.9 \\
$h_{\mathrm{i}}^{2}$ & $0.56 \pm 0.147$ & \\
$h_{\mathrm{hs}}^{2}$ & $0.97 \pm 0.009$ & \\
Mean $\pm \mathrm{SE}$ & $0.496 \pm 0.007$ & \\
\hline
\end{tabular}

Note: The table provides values of observed variance components (estimate \pm approximate standard error), percentage of total variance explained by factors in the model, and narrow-sense individual-tree $\left(h_{\mathrm{i}}^{2}\right)$ and family-mean $\left(h_{\mathrm{hs}}^{2}\right)$ heritabilities for rust disease. The check lot was excluded from the analysis.

where the pathogen population may contain a mixture of virulence types, some portion of which can overcome the resistance alleles present in the mother tree. The contribution of major-gene resistance alleles from the pollen pool is likely to be low, based on a previous report (Wilcox et al. 1996), but could vary between open-pollinated seed lots depending on the genotypes of pollen parents in the orchards where each seed lot was collected.

\section{Breeding values of families from artificial inoculations and comparisons with field trials}

The predicted breeding values of families across the greenhouse inoculations showed considerable variation, par- 
Table 3. Shukla stability variance for each family $\left(\sigma_{\mathrm{i}}^{2}\right)$, probability $(P)$ of $Z$ value testing the significance level of $\sigma_{\mathrm{i}}^{2}$, percentage of the stability variance ( $\%$ of $\left.\sigma_{\mathrm{i}}^{2}\right)$, least-squares means (LS means) for families across inocula, and family groups based on LS differences.

\begin{tabular}{|c|c|c|c|c|c|c|}
\hline $\begin{array}{l}\text { Family type } \\
\text { from field trials }\end{array}$ & $\begin{array}{l}\text { Family } \\
\text { No. }\end{array}$ & $\sigma_{\mathrm{i}}^{2}$ & $P$ & $\%$ of $\sigma_{i}^{2}$ & LS means (SE) & $\begin{array}{l}\text { Family } \\
\text { grouping }^{a}\end{array}$ \\
\hline Resistant & 23 & 0 & - & 0.0 & $0.12(0.029)$ & $\mathrm{K}$ \\
\hline Resistant & 16 & 0 & - & 0.0 & $0.17(0.029)$ & JK \\
\hline Resistant & 24 & 0.0019 & 0.265 & 1.7 & $0.22(0.032)$ & IJ \\
\hline Resistant & 13 & 0 & - & 0.0 & $0.22(0.030)$ & IJ \\
\hline Resistant & 19 & 0.0501 & 0.026 & 43.8 & $0.24(0.076)$ & GHIJK \\
\hline Resistant & 6 & 0 & - & 0.0 & $0.29(0.029)$ & $\mathrm{H}$ \\
\hline Resistant & 21 & 0.0096 & 0.076 & 8.4 & $0.30(0.042)$ & GHI \\
\hline Resistant & 14 & 0.0040 & 0.160 & 3.5 & $0.33(0.035)$ & FGH \\
\hline Resistant & 17 & 0.0047 & 0.143 & 4.1 & $0.36(0.036)$ & FGH \\
\hline Resistant & 10 & 0.0009 & 0.363 & 0.8 & $0.36(0.030)$ & FG \\
\hline Resistant & 27 & 0.0065 & 0.107 & 5.7 & $0.38(0.039)$ & FG \\
\hline Resistant & 15 & 0.0027 & 0.221 & 2.3 & $0.40(0.033)$ & $\mathrm{F}$ \\
\hline Susceptible & 18 & 0.0049 & 0.137 & 4.3 & $0.53(0.036)$ & $\mathrm{E}$ \\
\hline Resistant & 30 & 0.0021 & 0.251 & 1.9 & $0.59(0.032)$ & $\mathrm{DE}$ \\
\hline Susceptible & 12 & 0.0026 & 0.225 & 2.2 & $0.60(0.033)$ & $\mathrm{DE}$ \\
\hline Susceptible & 4 & 0 & - & 0.0 & $0.60(0.029)$ & $\mathrm{DE}$ \\
\hline Resistant & 29 & 0.0111 & 0.067 & 9.7 & $0.62(0.044)$ & $\mathrm{BCDE}$ \\
\hline Susceptible & 2 & 0.0052 & 0.130 & 4.6 & $0.62(0.037)$ & $\mathrm{CD}$ \\
\hline Resistant & 22 & 0.0008 & 0.379 & 0.7 & $0.63(0.030)$ & $\mathrm{CD}$ \\
\hline Susceptible & 11 & 0.0017 & 0.287 & 1.5 & $0.65(0.032)$ & $\mathrm{BCD}$ \\
\hline Checklot & 39 & 0 & - & 0.0 & $0.68(0.029)$ & $\mathrm{BC}$ \\
\hline Resistant & 20 & 0.0018 & 0.280 & 1.5 & $0.69(0.032)$ & $\mathrm{BC}$ \\
\hline Susceptible & 25 & 0.0028 & 0.215 & 2.4 & $0.70(0.033)$ & $\mathrm{BC}$ \\
\hline Resistant & 28 & 0 & - & 0.0 & $0.70(0.029)$ & $\mathrm{B}$ \\
\hline Susceptible & 5 & 0 & - & 0.0 & $0.71(0.029)$ & $\mathrm{AB}$ \\
\hline Susceptible & 3 & 0.0009 & 0.366 & 0.8 & $0.77(0.030)$ & A \\
\hline
\end{tabular}

Note: For the 25 experimental families, type represents the original assessment of resistance level based on prior field data. The check lot is not a single family but for ease of presentation in the table no distinction has been made. $\sigma_{\mathrm{i}}^{2}$ is considered significant at $P \leq 0.10$; significant values are in bold.

${ }^{a}$ Families sharing one or more letters are not significantly different for rust disease incidence.

ticularly among the field-resistant families (Fig. 3). For greenhouse inoculations, the best linear unbiased predicted disease incidence breeding values of families ranged from 0.12 to 0.73 for the field-resistant families, whereas the range of breeding values among the field-susceptible families was smaller, i.e., from 0.53 to 0.77 . The check lot had a mean disease incidence probability of 0.68 .

The probabilities of disease incidence (breeding values) for the field-susceptible families were very similar in the field and in the greenhouse - if a family was susceptible in the field, it was susceptible in the greenhouse. Families in the field-resistant group showed considerably more disease in the greenhouse than in the field (Fig. 3). The results suggest that many pathogen sources, even at presumed low field inoculum densities, will cause disease in the susceptible families, whereas the resistant families apparently are protected, at least to some extent, from disease at the presumed low levels of inoculum in most field trials. In the greenhouse inoculations, the mixture of spores from 30 galls in each of the inocula may have included many different pathogen types, some able to overcome the resistance present in the host plants, thereby leading to higher disease incidence in response to controlled inoculations. Previous work has shown that major-gene $(F r l)$ resistance to fusiform rust in loblolly pine was not overcome by high inoculum load, unless the inoculum contained spores with specific virulence against the Frl resistance allele present in the host (Kuhlman et al. 1997). This suggests that the higher levels of disease incidence among field-resistant families in the greenhouse experiments is not due solely to the higher inoculum load, but also is likely to be related to the amount of variation in the 30-gall inoculum mix (e.g., increased probability of having a pathogen type that can overcome resistance) used in the greenhouse studies.

Consistent with the findings of previous reports on the correlation between greenhouse inoculation trials and fieldresistance data (Powers and Kuhlman 1987; Powers and Kraus 1983$)$, the high family repeatability values $\left(h_{\mathrm{hs}}^{2}\right)$ suggest that screening families in greenhouse inoculations and deploying selected resistant families would be very effective. Mass selection of individual trees or selection of individual seedlings within families after screening in greenhouse trials may also provide considerable genetic gains, but may not be as reliable as family selection because of smaller narrow-sense individual-tree heritabilities.

\section{Host family by pathogen bulked population interactions}

Shukla's stability statistics were estimated to partition the host pine family by fusiform rust inocula interaction (GEI) variance and assign it to individual families (Table 3 ). The 
higher the stability statistic, the more interactive or unstable the pine genotype is considered to be. "Stable" or "unstable" terms used for pine families in this study refer to the stability variances for families estimated from partitioning of GEI variance. The field-resistant family 19 was exceptionally interactive with the pathogen populations and explained about $44 \%$ of the total GEI variance. This family was also one of the most resistant, with an overall disease probability of 0.24 in the greenhouse study. Two other field-resistant families (29 and 21) also showed significant Shukla's stability statistics. Each contributed less than $10 \%$ to the total GEI interaction variance, although family 29 showed significantly higher disease incidence than family 21 . Family 2 was the most interactive (but still nonsignificant) field-susceptible family, explaining about $4.6 \%$ of the GEI variance. We did not observe a relationship between the greenhouse disease level of pine families and their stability values. For example, the three most resistant families $(23,16$, and 13) were also very stable across the 10 inocula; this finding is similar to what was observed for the highly diseased field-susceptible families. The check lot, as suggested by very small stability statistics $\left(\sigma_{\mathrm{i}}^{2}\right)$, was very stable, developing a high disease incidence across all inocula.

The mixed model fit to estimate Shukla's stability statistics allows comparison of families according to the Shukla's stability variance (Table 3). We observed two distinct groups according to disease incidence levels. The first group (with letters $\mathrm{F}$ to $\mathrm{K}$ in Table 3 ) contains families that were originally classified as field resistant, and the second group (with letters A to E in Table 3) is a mixture of five field-resistant and of all the field-susceptible families, as well as the check lot. This separation into resistant and susceptible families based on analysis of variance of the results of greenhouse inoculations agrees completely with the criterion used by Kuhlman (1992), which is that resistant families have less than $70 \%$ of the disease incidence of the susceptible check lot.

A highly interactive family (such as 19) is difficult to explain within the traditional infinitesimal polygenic model of disease resistance, which is generally considered stable. However, within the previously proposed framework of major-gene resistance to fusiform rust in loblolly pine (Wilcox et al. 1996; Amerson et al. 2005), this instability could be due to the existence of one or more resistance genes in that family, which confer resistance to many sources of the pathogen, but can be routinely overcome if the inoculum contains a high proportion of pathogen spores with virulence against those resistance alleles.

Mother trees with low disease breeding values (even one with progeny that were highly interactive) can be generally useful in breeding for rust resistance because they already contain resistance to many sources of the pathogen. Specific crosses can be made to combine complementary resistance patterns, such as parent $6 \times$ parent 19 to combine resistance to inocula 301 and 302 (from parent 6) with resistance to inocula 309 and 310 (from parent 19) (see Appendix A, Table A1 for details). Families 23, 16, 24, 13, and 6 are the most resistant genotypes with good stability and are the most likely families to have low disease incidence across a wide geographic range in the southeastern United States. Families recognized as resistant in this study could also be useful for discovering new major-gene rust resistance alleles, and such experiments using single genotype line inocula are underway.

\section{Conclusions}

There were highly significant differences among families in response to inoculations. Genetic differences among families explained $13.7 \%$ of the total variation. Significant pathogenic variability was observed among the inoculum sources, although inocula accounted for only $1.9 \%$ of the variance overall. The mean disease incidence across all 25 pine families and the check lot caused by each of the inocula ranged from 0.34 to 0.57 , but a single inoculum could have a range of disease incidences of 0.83 on different families (Appendix A, Table A1). The greater fraction of variation explained by host family than by pathogen inoculum is probably due to the presence of a greater genetic diversity both within and between the mixed inocula (e.g., each inoculum mix was prepared from 30 wild field-collected galls). Each pine family represents primarily the genetic variation in a single mother tree, because rust resistance (at least major gene resistance) seems to be relatively rare in the pollen pool (Wilcox et al. 1996). Because resistance to fusiform rust is a highly heritable trait, as shown by high familymean heritability (Table 2), a family and within-family index selection for resistance to fusiform rust disease based on results of greenhouse inoculations would be highly efficient. Overall, family by pathogen inocula interaction was significant. However, one field-resistant family contributed about $44 \%$ of the total family by pathogen interaction variance. The majority of families were stable, i.e., showed no significant interaction with different inocula.

Although the three most interactive (unstable) families were classified as field resistant, an analysis of the greenhouse inoculations using Shukla's stability variance does not support the hypothesis that field-resistant families, on average, are more interactive (unstable) than field-susceptible families. This hypothesis was formulated on the analysis reported by McKeand et al. (2003) for field test results. The use of mixed inocula, with each inoculum composed of spores derived from 30 field-collected galls, in the greenhouse tests reported here may affect the ability to detect interactions, because the effects of genetic variation in the pathogen population are averaged across the mixture of pathogen genotypes.

\section{References}

Amerson, H.V., Kubisiak, T.L., Garcia, S.A., Kuhlman, E.G., Nelson, C.D., and McKeand, S.E. Mullin, T.J., and Li, B. (2005) Interacting genes in the pine-fusiform rust forest pathosystem. In Proccedings of the 28th Southern Forest Tree Improvement Conference, 21-23 June 2005, Raleigh, N.C. Edited by S.E. McKeand and B. Li. p. 60. Available from http://www.rngr.net/ Publications/sftic/2005 [accessed 8 September 2008].

Anderson, R.L., McClure, J.P., Cost, N.D., and Uhler, R.J. 1986. Estimating fusiform rust losses in five southeast states. South. J. Appl. For. 10: 237-240.

Browne, W.J., Subramanian, S.V., Jones, K., and Goldstein, H. 2005. Variance partitioning in multilevel logistic models that exhibit overdispersion. J. R. Stat. Soc. [Ser. A], 168: 599-613. doi:10.1111/j.1467-985X.2004.00365.x.

Cubbage, F., Pye, J., Holmes, T., and Wagner, J. 2000. An eco- 
nomic analysis of fusiform rust protection research. South. J. Appl. For. 24: 77-85.

Falconer, D.S., and Mackay, T.F.C. 1996. Introduction to quantitative genetics. 4th ed. Longman Group Ltd, Essex, UK.

Gilmour, A.R., Anderson, R.D., and Rae, A.L. 1985. The analysis of binomial data by a generalized linear mixed model. Biometrika, 72: 593-599. doi:10.1093/biomet/72.3.593.

Gilmour, A.R., Anderson, R.D., and Rae, A.L. 1987. Variance components on an underlying scale for ordered multiple threshold categorical data using a generalized linear mixed model. J. Anim. Breed. Genet. 104: 149-155.

Goldstein, H., Browne, W.J., and Rasbash, J. 2002. Partitioning variation in multilevel models. Understand. Statist. 1: 223-231. doi:10.1207/S15328031US0104_02.

Isik, F., Goldfarb, B., LeBude, A., Li, B., and McKeand, S. 2005. Predicted genetic gains and testing efficiency from two loblolly pine clonal trials. Can. J. For. Res. 35: 1754-1766. doi:10.1139/ x05-064.

Isik, F., Gumpertz, M., Li, B., Goldfarb, B., and Sun, X. 2008. Analysis of cellulose microfibril angle (MFA) using a linear mixed model in Pinus taeda clones. Can. J. For. Res. 38: 16761689. doi:10.1139/X08-010.

Kang, M.S., and Magari, R. 1996. New developments in selecting for phenotypic stability in crop breeding. In genotype by environment interaction. Edited by M.S. Kang and H.G. Gauch Jr. CRC Press, Boca Raton, Fla. pp. 1-14.

Kinloch, B.B., and Stonecypher, R.W. 1969. Genetic variation in susceptibility to fusiform rust in seedlings from a wild population of loblolly pine. Phytopathology, 59: 1246-1255.

Kinloch, B.B., and Walkinshaw, C.H. 1991. Resistance to fusiform rust in southern pines: how is it inherited? In Rusts of Pine. Proceedings IUFRO Rusts of Pine Working Party Conference. Edited by Y. Hiratsuka et al. For. Can. Northwest. Reg. Info. Rep. NOR-X-317, Edmonton, Alta. pp. 219-228.

Knighten, J.L., Young, C.H., McCartney, T.C., and Anderson, R.L. 1988. Resistance screening center procedures manual: a step by step guide used in the operational screening of southern pines for resistance to fusiform rust. USDA For. Serv. For. Pest Manage. Rep. 83-1-18 [revised 1988].

Kuhlman, E.G. 1992. Interaction of virulent single-gall isolates of Cronartium quercuum f.sp. fusiforme and resistant families of loblolly pine. For. Sci. 38: 641-651.

Kuhlman, E.G., and Powers, H.R., Jr. 1988. Resistance responses in half-sib loblolly pine progenies after inoculation with Cronartium quercuum f.sp. fusiforme. Phytopathology, 78: 484-487. doi:10.1094/Phyto-78-484.

Kuhlman, E.G., and Matthews, F.R. 1993. Variation in virulence among single-aeciospore isolates from single-gall isolates of Cronartium quercuum f.sp. fusiforme. Can. J. For. Res. 23: 6771. doi:10.1139/x93-011.

Kuhlman, E.G., Amerson, H.V., Jordan, A.P., and Pepper, W.D. 1997. Inoculum density and expression of major gene resistance to fusiform rust disease in loblolly pine. Plant Dis. 81: 597-600. doi:10.1094/PDIS.1997.81.6.597.

Li, H. 2003. Major gene detection for fusiform rust resistance using segregation analysis and linkage analysis in loblolly pine. Ph.D. thesis, North Carolina State University, Raleigh, N.C.

Li, B., and McKeand, S.E. 1989. Stability of loblolly pine families in the southeastern U.S. Silvae Genet. 38: 96-101.

Li, H., Ghosh, S., Amerson, H., and Li, B. 2006. Major gene detection for fusiform rust resistance using Bayesian complex segregation analysis in loblolly pine. Theor. Appl. Genet. 113: 921929. doi:10.1007/s00122-006-0351-x. PMID:16896716.
Lynch, M., and Walsh, B. 1998. Genetics and analysis of quantitative traits. Sinauer Associates, Inc., Sunderland, Mass.

McKeand, S., Li, B., and Amerson, H.V. 1999. Genetic variation in fusiform rust resistance in loblolly pine across a wide geographic range. Silvae Genet. 48: 255-260.

McKeand, S.E., Amerson, H.V., Li, B., and Mullin, T.J. 2003. Families of loblolly pine that are the most stable for resistance to fusiform rust are the least predictable. Can. J. Res. 33: 13351339. doi:10.1139/x03-050.

McKeand, S.E., Li, B., Grissom, J.E., Isik, F., and Jayawickrama, K.J.S. 2008. Genetic parameter estimates for growth traits from diallel tests of loblolly pine throughout the southeastern United States. Silvae Genet. 57: 101-110.

Powers, H.R., Jr. 1980. Pathogenic variation among single-aeciospore isolates of Cronartium quercuum $\mathrm{f}$. sp. fusiforme. For. Sci. 26: $280-282$.

Powers, H.R., Jr., and Kraus, J.F. 1983. Developing fusiform rustresistant loblolly pine and slash pine. Plant Dis. 67: 187-189.

Powers, H.R., Jr., and Kraus, J.F. 1986. A comparison of fusiform rust-resistant loblolly pine seed sources. South. J. Appl. For. 10: 230-232.

Powers, H.R., Jr., and Kuhlman, E.G. 1987. Resistance of loblolly pine sources to fusiform rust in field progeny tests. USDA For. Serv. Southeast. For. Exper. Stn. Res. Pap. SE-268. Available from at http://www.srs.fs.usda.gov/pubs/rp/rp_se268.pdf [accessed 8 September 2008].

Powers, H.R., Jr., Schmidt, R.A., and Snow, G.A. 1981. Current status and management of fusiform rust on southern pines. Annu. Rev. Phytopathol. 19: 353-371. doi:10.1146/annurev.py. 19.090181.002033.

Powers, H.R., Jr., Matthews, F.R., and Dwinell, L.D. 1977. Evaluation of pathogenic variability of Cronartium fusiforme on loblolly pine in the southern USA. Phytopathology, 67: 14031407.

SAS Institute Inc. 1996. SAS/STAT software: changes and enhancements (through release 6.11). SAS Institute Inc., Cary, N.C.

Saxton, A. (Editor). 2004. Genetic analysis of complex traits using SAS. SAS Institute Inc., Cary, N.C.

Schall, R. 1991. Estimation in generalized linear models with random effects. Biometrika, 78: 719-727. doi:10.1093/biomet/78.4. 719.

Schmidt, R.A., Powers, H.R., Jr., and Snow, G.A. 1981. Application of genetic disease resistance for the control of fusiform rust in intensively managed southern pine. Phytopathology, 31: 993-997.

Shukla, G.K. 1972. Some statistical aspects of partitioning genotype-environmental components of variability. Heredity, 29: 237-245. doi:10.1038/hdy.1972.87. PMID:4507945.

Snow, G.A., Dinus, R.A., and Kais, A.G. 1975. Variation in pathogenicity of diverse sources of Cronartium fusiforme on selected slash pine families. Phytopathology, 65: 170-175.

Tempelman, R.J. 1998. Generalized linear mixed models in dairy cattle breeding. J. Dairy Sci. 81: 1428-1444. PMID:9621247.

Walkinshaw, C.H., and Bey, C.F. 1981. Reaction of field-resistant slash pine to selected isolates of Cronartium quercuum f.sp. fusiforme. Phytopathology, 71: 1090-1092.

Wilcox, P.L., Amerson, H.V., Kuhlman, E.G., Liu, B.H., O'Malley, D.M., and Sederoff, R.R. 1996. Detection of a major gene for resistance to fusiform rust disease in loblolly pine by genomic mapping. Proc. Natl. Acad. Sci. U.S.A, 93: 3859-3864. doi:10. 1073/pnas.93.9.3859. PMID:8632980.

Xiang, B., and Li, B. 2001. A new mixed analytical method for genetic analysis of diallel data. Can. J. For. Res. 31: 2252-2259. doi:10.1139/cjfr-31-12-2252. 


\section{Appendix A}

Table A1. Response of pine families and check lot (probability of disease) when challenged with different Cronartium quercuum f.sp. fusiforme bulked inocula populations.

\begin{tabular}{|c|c|c|c|c|c|c|c|c|c|c|c|c|c|}
\hline \multirow[b]{2}{*}{$\begin{array}{l}\text { Type (based on } \\
\text { field trials) }\end{array}$} & \multirow[b]{2}{*}{$\begin{array}{l}\text { Family } \\
\text { No. }\end{array}$} & \multirow[b]{2}{*}{$\%$ of $\sigma_{i}^{2}$} & \multicolumn{10}{|c|}{ Inoculum (name and code) } & \multirow[b]{2}{*}{$\begin{array}{l}\text { Family } \\
\text { means }\end{array}$} \\
\hline & & & $\begin{array}{l}\text { East TX, } \\
301\end{array}$ & $\begin{array}{l}\text { Cent. LA, } \\
302\end{array}$ & $\begin{array}{l}\text { S East LA, } \\
303\end{array}$ & $\begin{array}{l}\text { South. AL, } \\
304\end{array}$ & $\begin{array}{l}\text { N East FL, } \\
305\end{array}$ & $\begin{array}{l}\text { Cent. GA, } \\
306\end{array}$ & $\begin{array}{l}\text { Coast GA } \\
\text { SC, } 307\end{array}$ & $\begin{array}{l}\text { Pied. SC, } \\
308\end{array}$ & $\begin{array}{l}\text { Pied. GA, } \\
309\end{array}$ & $\begin{array}{l}\text { N Coast SC, } \\
310\end{array}$ & \\
\hline Resistant & 23 & 0.0 & 0.09 & 0.10 & 0.12 & 0.12 & 0.12 & 0.10 & 0.12 & 0.07 & 0.16 & 0.25 & 0.12 \\
\hline Resistant & 16 & 0.0 & 0.04 & 0.10 & 0.25 & 0.12 & 0.22 & 0.07 & 0.20 & 0.17 & 0.18 & 0.33 & 0.17 \\
\hline Resistant & 13 & 0.0 & 0.26 & 0.18 & 0.21 & 0.00 & 0.27 & 0.16 & 0.22 & 0.22 & 0.31 & 0.33 & 0.22 \\
\hline Resistant & 24 & 1.7 & 0.12 & 0.17 & 0.17 & 0.18 & 0.17 & 0.09 & 0.33 & 0.33 & 0.25 & 0.40 & 0.22 \\
\hline Resistant & 19 & $43.8 *$ & 0.63 & 0.63 & 0.07 & 0.19 & 0.26 & 0.09 & 0.29 & 0.12 & 0.09 & 0.05 & 0.24 \\
\hline Resistant & 6 & 0.0 & 0.19 & 0.28 & 0.22 & 0.25 & 0.34 & 0.13 & 0.33 & 0.27 & 0.45 & 0.43 & 0.29 \\
\hline Resistant & 21 & $8.4^{* *}$ & 0.25 & 0.47 & 0.43 & 0.20 & 0.17 & 0.17 & 0.17 & 0.29 & 0.40 & 0.48 & 0.30 \\
\hline Resistant & 14 & 3.5 & 0.47 & 0.18 & 0.26 & 0.26 & 0.36 & 0.15 & 0.43 & 0.37 & 0.47 & 0.32 & 0.33 \\
\hline Resistant & 17 & 4.1 & 0.35 & 0.33 & 0.44 & 0.50 & 0.30 & 0.25 & 0.35 & 0.27 & 0.43 & 0.33 & 0.36 \\
\hline Resistant & 10 & 0.8 & 0.40 & 0.44 & 0.28 & 0.26 & 0.35 & 0.15 & 0.30 & 0.40 & 0.46 & 0.55 & 0.36 \\
\hline Resistant & 27 & 5.7 & 0.40 & 0.34 & 0.53 & 0.41 & 0.35 & 0.18 & 0.55 & 0.30 & 0.33 & 0.40 & 0.38 \\
\hline Resistant & 15 & 2.3 & 0.50 & 0.37 & 0.50 & 0.41 & 0.40 & 0.27 & 0.33 & 0.42 & 0.40 & 0.37 & 0.40 \\
\hline Susceptible & 18 & 4.3 & 0.62 & 0.38 & 0.61 & 0.42 & 0.60 & 0.32 & 0.58 & 0.52 & 0.50 & 0.77 & 0.53 \\
\hline Resistant & 30 & 1.9 & 0.55 & 0.60 & 0.42 & 0.45 & 0.73 & 0.48 & 0.72 & 0.58 & 0.70 & 0.68 & 0.59 \\
\hline Susceptible & 12 & 2.2 & 0.54 & 0.67 & 0.65 & 0.47 & 0.67 & 0.40 & 0.67 & 0.45 & 0.73 & 0.75 & 0.60 \\
\hline Susceptible & 4 & 0.0 & 0.63 & 0.63 & 0.46 & 0.59 & 0.60 & 0.41 & 0.59 & 0.63 & 0.72 & 0.75 & 0.60 \\
\hline Resistant & 29 & $9.7 * *$ & 0.75 & 0.55 & 0.75 & 0.78 & 0.59 & 0.51 & 0.61 & 0.45 & 0.56 & 0.67 & 0.62 \\
\hline Susceptible & 2 & 4.6 & 0.49 & 0.54 & 0.42 & 0.63 & 0.74 & 0.55 & 0.65 & 0.75 & 0.72 & 0.73 & 0.62 \\
\hline Resistant & 22 & 0.7 & 0.60 & 0.62 & 0.52 & 0.67 & 0.80 & 0.42 & 0.68 & 0.55 & 0.73 & 0.74 & 0.63 \\
\hline Susceptible & 11 & 1.5 & 0.52 & 0.70 & 0.70 & 0.57 & 0.78 & 0.57 & 0.57 & 0.68 & 0.72 & 0.68 & 0.65 \\
\hline Checklot & 39 & 0.0 & 0.68 & 0.68 & 0.60 & 0.62 & 0.78 & 0.52 & 0.62 & 0.77 & 0.73 & 0.75 & 0.68 \\
\hline Resistant & 20 & 1.5 & 0.78 & 0.78 & 0.63 & 0.59 & 0.65 & 0.57 & 0.73 & 0.70 & 0.62 & 0.80 & 0.69 \\
\hline Susceptible & 25 & 2.4 & 0.77 & 0.67 & 0.47 & 0.62 & 0.80 & 0.57 & 0.71 & 0.65 & 0.82 & 0.88 & 0.70 \\
\hline Resistant & 28 & 0.0 & 0.66 & 0.74 & 0.76 & 0.62 & 0.81 & 0.52 & 0.78 & 0.65 & 0.75 & 0.73 & 0.70 \\
\hline Susceptible & 5 & 0.0 & 0.75 & 0.55 & 0.68 & 0.70 & 0.77 & 0.57 & 0.68 & 0.70 & 0.78 & 0.87 & 0.71 \\
\hline Susceptible & 3 & 0.8 & 0.76 & 0.77 & 0.73 & 0.83 & 0.87 & 0.72 & 0.72 & 0.70 & 0.83 & 0.73 & 0.77 \\
\hline Inoculum means & & & 0.49 & 0.48 & 0.46 & 0.44 & 0.52 & 0.34 & 0.50 & 0.46 & 0.53 & 0.57 & 0.48 \\
\hline
\end{tabular}

Note: Families and the check lot are sorted based on overall means across all inocula in the greenhouse screening trials. *, percentage of Shukla's variance $\left(\sigma_{\mathrm{i}}^{2}\right)$ is significant at a probability level of 0.05 ; $* *, \%$ of $\sigma_{\mathrm{i}}^{2}$ is significant at a probability level of 0.10 . 